Таким образом, возникает проблема реализации гендерной идентичности личности на разных этапах жизненного пути, в разных социокультурных средах и бытийных пространствах. Она в свою очередь актуализирует и определяет проблему исследования, заключающуюся в новом теоретическом осмыслении и эмпирическом изучении смысловых механизмов реализации гендерной идентичности личности, обеспечивающих преобразование внешних гендерных норм, образцов и ролей в индивидуализированный опыт личности и определяющих особенности и направления реализации гендерной идентичности в различных пространствах бытия личности.

\title{
Литература
}

1. Котлова Т.Б., Рябова Т.Б. Библиографический обзор исследований по проблемам гендерных стереотипов // Женщина в Российском обществе - №1. 2002. C. 25-33.

2. Майерс Д. Социальная психология. - СПб.: Питер, 1998. - С. 256-267.

3. Минорова С.А., Кустова О.Л. Формирование образа жизни в различных социальных группах // Журнал практического психолога. - 1997. №5. - C. 27-29.

4. Николаева Е. Мужчина и женщина глазами психофизиолога / Под ред. Т.В. Барчуновой. - Новосибирск, 1998. - С. 62-81.

5. Общество в гендерной перспективе: Сборник статей / Сост. Е.Г. Луговицкая. - Новгород, 2002. - С. 62-81.

6. Райс Ф. Психология подросткового и юношеского возраста. СПб.: «Питер». 2008.

7. Кон И.С. Психология половых различий. //Вопросы психологии. 2005.

8. Возрастно-психологические особенности гендерных образов. //Семейная психология и семейная терапия, 2008, № 1.

9. Образы мужчины и женщины в истории России, Вопросы гуманитарных наук, 2008

\section{ПОНЯТИЕ «РЕСУРСА» ЛИЧНОСТИ (К ПОСТАНОВКЕ ПРОБЛЕМЫ)}

\section{Липчевская В.Л., Тесля С.Н.}

Понятие «ресурс» выражает качественный потенциал социальнопсихологической активности социального субъекта при осуществлении им субъектности, как своего главного способа бытия. Ресурсность или потенциальность качества этой активности - субъектности - проявляется в различных действительных свойствах субъекта при взаимодействии со средой, самим собой, другим и социумом в целом. В этой связи актуальной задачей становится выявление типологических особенностей свойств активности социального субъекта, позволяющих рассматривать его как многовариантный объект социально-психологического изучения и эмпирических исследований и в то же время, прогнозировать возможности его субъектности [1,с. 396]. 
В истории отечественной психологии личности, в зарубежной персонологии есть глубокие и всесторонние характеристики человека, обосновывающие его продуктивную природу, благодаря которой он порождает новые и иные горизонты бытия, оставаясь «мерой всем вещам». В категориальной сетке человека находим и такие понятия как «субъект», «индивид», «индивидуальность», «личность». Как правило, значение одного из них раскрывается через другое, даже на уровне философской методологии, часто они используются как синонимы, более того, производные от «личности» термины «личностный» и «личный» зачастую синонимизируются. В такой синкретической картине умножения понятий упускаются значимые характеристики человека, не случайно обобщенные в различных категориях.

Таким образом, появляется возможность дифференцировать категории «индивид», «индивидуальность», «личность» - прежде всего, по критерию субъектности социального субъекта. Она понимается как активность особого рода, связанная со способностью субъекта изменять, преобразовывать средуобъект в соответствие со своими рациональными целями и субъективным выбором. «Изменение» и «преобразование» в этом контексте есть социальные аналоги «порождающей» активности субъекта жизни, могут быть приняты в качестве критерия социальной валидности и эффективности деятельности индивидуума или группы в различных сценах идентификации.

Рассмотрим понятие «ресурс». Мы можем назвать это «жизненной силой», энергетикой, ему придается определяющее значение, в связи с тем, что человек воспринимается, прежде всего, как активное существо. Поэтому - все, что выявляется и диагностируется, это - насколько человек вырос к своей активности. Если он показывает, проявляет ее, можно заключать о, более менее, гармоничном жизненном пути. Если этот актив никак не задействован, и человек даже не знает, что он у него есть, наверняка, у него могут быть проблемы - либо как внутренне воспринимаемая конфликтность, либо внешние отношения будут давать сбои, и значит, ресурсная активность это - константа человеческая, отменить ее нельзя. Ее назначение - усовершенствовать образ, который человек получает как обратную связь от окружающего. Он образует окружающее. Это такая установка, которую мы принимаем без доказательства: человек образует окружающую действительность сам [2,c.43].

В слове активность и способность образовывать что-либо, предполагается, что человек это делает свободно, самостоятельно. Этот момент спонтанности, свободы - образовывать окружающее - связан с реализацией его человеческой константы, а, значит, в целом, с удовлетворением жизнью. В этом тезисе выражена основная идея ресурса.

Для чего все это человек делает? - Для того чтобы расти. Если человек подключается к смыслу роста, - у него все в порядке, все хорошо.

Итак, образование действительности раскрывает смысл активности. Насколько эта активность присутствует в каждом из нас, описывает понятие «ресурс».

Диагностика ресурса, и, на ее основе, формирование представления о возможной и действительной полноте роста, очень важна. И исследовательский 
интерес заключается в том, чтобы выяснить, есть ли у роста ресурсы и каковы их критерии. Ясно, что мы подошли к ведущей гипотезе: такие критерии есть. Но, прежде чем эти критерии ввести, сделаем ряд пояснений и представим логику суждения.

Предполагается, что критерии - единые для каждого ресурса. Ресурсов в каждом из нас несколько. Признается, что какой-то один из ресурсов ведущий. Это не означает, что других ресурсов нет. Просто, один окрашивает собою все остальные. У него своя задача, свое амплуа, своя миссия. Но и у других ресурсов тоже есть свои идеальные смыслы и, одновременно, сравнительно фиксированные значения. Логика ресурсов уходит в трехчастный принцип, принцип триады. Логика, в каждом из нас, базируется на принципе триады.

Итак, есть, как бы, генеральный, универсальный ресурс в человеке, ресурс как таковой, как принцип жизненности. А есть несколько частных ресурсов внутри самого главного жизненного ресурса. Стремление к интегралу задается реализацией каждого ресурса в полной мере. Если каждый из них будет реализован, при том, что ведущий окрасит все остальные, тогда у человека есть возможность выйти на систему в себе. Каждый из нас потенциально воплощает некий «комок» жизненности, жизненной энергетики. У жизни этой нет никакого другого смысла, кроме как расти и никогда не оканчиваться, находиться в самом темпорале, внутри процесса этого роста. То есть, субъект не просто существо, стихийно куда-то растущее. Он - саморегулирующаяся и самоорганизующаяся система, и каждый новый виток на стволе его роста, это иное, новое состояние жизни.

Таким образом, получается, что вся предложенная логика «работает» на идею «чувства жизни», на идею жизни, которая сама собою организуется в субъекте и никогда не заканчивается. Момент этой «самости» следует объяснить. В современной психологии очень распространены термины «субъект» и «субъектность». «Субъектность» объясняет несколько с другой стороны понятие «активность» [3]. Когда человек проявляет свою субъектность? - С одной стороны, тогда, когда возникает момент его свободного поступка, свободного действия, не запрограммированного ничем из социально-заданных стереотипов поведения, каких-то программ и, в целом, норм, когда человек стоит на грани: все, что было - это одно, а нужно сделать совершенно самостоятельный, новый шаг, связанный с продолжением момента роста. Оказывается, что «расти» - это не просто подключиться к какому-то энергетическому потоку. Тут требуется всегда делать усилие. Этому усилию часто предшествует страх нового, его зачин переживается как беспокойство, сомнение. Но если он сможет удержаться в состоянии этой неопределенности и не пойти на поводу у страха, но сделать чуть-чуть шаг вперед, здесь он и проявит свою субъектность, произведет новый образ жизни, который преобразить его самого.

Итак, тезис: порождение нового, преображение. Ресурс работает так, что человек все время стремится к иному, к чему-то, если не противоположному, то дополняющему, расширяющему его возможности. Иногда, действительно, 
стремится к прямо противоположному. И вот здесь проявляется момент рождающегося субъекта: он рождает, и поэтому растет! Собственно, этот момент порождения и принимается нами в качестве смысла жизни, и этот смысл вложен в диагностику всех ресурсов.

Психологу предстоит правильно выбрать метод и язык общения: как беседовать, начинать с клиентом работать, как создать ему такую атмосферу, чтобы он проявил свой жизненный потенциал. Важно понимать, что все ресурсы по отношению друг к другу находятся в паритете. Только у субъекта есть предпочтение проявить тот или иной ресурс в данной жизненной ситуации. Но вместе с тем, у субъекта как целостного существа, может быть стратегический, судьбинный, ведущий ресурс, актуализация которого в ходе встреч с психологом, поможет ему гармонизировать себя и по другим ресурсам.

\section{Литература}

1. Тесля С.Н. Личностный ресурс учителя как критерий его социальной идентичности / Университетское образование современного педагога: Сборник научных статей Всероссийской научно-практической конференции 13 октября 2016 года /Под ред. И.В. Гладкой, С.А. Писаревой. СПб: Изд-во РГПУ им. А.И. Герцена, 2016. - С. 395-401.

2. Исаченко А.Ю., Тесля С.Н.. Шашков А.В. Психологическое консультирование: экзистенциально-гуманистическое консультирование: учебное пособие. - Сочи: РИЦ ФГБОУ ВПО «СГУ», 2015. - С.42-48.

3. Тесля С.Н. Понятия «субъектный подход», «субъектность» и «человек как субъект жизни» / Материалы Международной науч. конф. Человек, Субъект. Личность в современной психологии Посв.80 - летию А.В.Брушлинского, 10-11окт. 2013года, Москва. Отв.ред. А.Л. Журавлев, Е.А.Сергиенко. - М.: Издательство «Институт Психологии РАН», 2013.Т.1. C.355-358.

\section{СПЕЦИФИКА СУБЪЕКТИВНОЙ КАРТИНЫ ЖИЗНЕННОГО ПУТИ У ЖЕНЩИН С РАЗЛИЧНЫМ УРОВНЕМ УДОВЛЕТВОРЕННОСТИ БРАКОМ}

Макаревская И.Г.

Проблема жизненных перспектив личности, субъективной картины жизненного пути становится все более актуальной в современной психологии. Возрастание темпов жизни требует от человека более осмысленного отношения к времени собственной жизни, так как умение предвидеть, прогнозировать и строить жизненные планы влияют на жизненный выбор, организацию и осуществление деятельности. Жизненный путь является тем целостным специфическим процессом, в котором происходит функционирование, изменение и развитие личности.

Проблемой жизненного пути занимались отечественные и зарубежные исследователи: К.А.Абульханова-Славская, Б.Г.Ананьев, Л.И.Анцыферова, 